\title{
PROPOSING KYRGYZ YURTS AS A MARKETING TOOL FOR KYRGYZ AGRICULTURAL PRODUCTS
}

\author{
${ }^{I}$ Nazarmatova Burul Mukashovna Candidate of Economical Sciences, \\ ${ }^{2}$ Ibraev Almaz Orozakunovich Candidate of Political Sciences, \\ ${ }^{3}$ Ammar Younas Aspirant \\ Kyrgyzstan, Bishkek, \\ ${ }^{I}$ International Academy of Management, Law, Finance and Business, Head of International Relations \\ Department; \\ ${ }^{2}$ Eastern University named after Mahmud Kashgari Barskani, Rector; \\ ${ }^{3}$ Eastern University named after Mahmud Kashgari Barskani, Director of Eastern Center of Strategic Studies
}

DOI: https://doi.org/10.31435/rsglobal_ijite/01062018/5650

\section{ARTICLE INFO}

Received 02 April 2018

Accepted 01 May 2018

Published 01 June 2018

\section{KEYWORDS}

Yurt,

Kyrgyzstan,

Branding,

Marketing,

Agricultural Products

\begin{abstract}
The objective of this analytical document in to propose an idea of protecting the ancient knowledge of Yurt craftmanship, to personalize it with Kyrgyzstan and to use Yurt as a brand for all the Kyrgyz manufactured products especially for the marketing of export quality agriculture products. This proposal calls for a state level intervention which can ensure that the agriculture products of export quality as of beans from Talas Region of Kyrgyzstan should be exported by using Yurt as a logo on its packing so that the international market could recognize its origin and Kyrgyzstan could get better marketing benefits from it.
\end{abstract}

(C) 2018 The Authors.

Affiliation of Yurts with Kyrgyz Nomadic Life Style. Academia is working on highlighting the importance of nation buildings to the protection of individual's identity, from collecting empirical data in the favor of the status of religious symbols in public sphere to the promotion of logos and brands which represent distinct features of the producers. At the same time, academia is helping actively to the business community to think beyond the commercial benefits and to protect their ancient craftsmanship and at the same time helping their countries to overcome identity crisis.

One of the distinctive characters of Kyrgyz people is that they are nomadic and used to tend cattle, sheep, horses and yaks. They used to live in Nomadic homes called as Yurts. They used to travel between valleys and mountains depending on the availability of pastures and seasons. The neighboring Uzbeks were not nomadic where as Kazakhs were more nomadic than Kyrgyz. Kyrgyzstan is famous for its jailoos, high pastures used for grazing in summer. Unlike the Kazakhs and Mongols, who primarily migrated with their animals, long distance from summer pastures in the steppes to winter pastures in the semideserts, the Kyrgyz have traditionally migrated vertically between summer pastures in the mountains and winter grazing areas or settled farms in the valleys or lowlands. (1)

Yurts hold much of Kyrgyz culture, from important rituals and ceremonies, to craftsmanship and traditional artistry. Yurts can be found across Eurasia, though with slightly different materials, dimensions or traditions. Kyrgyz yurts are made of a cupola birch poles tied to a latticework that forms the vertical walls. The outside is made of felt and wool, which is water repellent and warm, and can be easily patched as needed. The top of the yurt is a wooden circle, called a tunduk, which forms one of the most essential symbols of family and the universe. A small flap of felt covers the tunduk, which can be opened when weather is nice to let in light and fresh air, and closed when the weather is cold and wet. The tunduk is one of the most essential designs in Kyrgyzstan and is used on the flag. The whole design of yurts was centered around being both portable and flexible, suitable for any season or location. (2)

In 2014, traditional knowledge and skills in making Kyrgyz and Kazakh yurts was placed on the UNESCO Intangible Heritage list. According to UNESCO: "The yurt is a nomadic dwelling used among the Kazakh and Kyrgyz peoples. It has a wooden circular frame covered with felt and braided with ropes, and can be easily assembled and dismantled within a short period of time. The bearers of 
yurt-making knowledge are craftspeople, both men and women, who produce yurts and their interior decorations. Yurts are made from natural and renewable raw materials. Men and their apprentices make the wooden frames by hand, along with wooden, leather, bone and metal details. Women make the interior decorations and exterior coverings, ornamented with traditional zoomorphic, vegetative or geometric patterns." According to UNESCO Kyrgyz and Kazakh yurt-making skills were placed on the UNESCO Intangible Heritage list because: Traditional yurt-making knowledge and skills are transmitted from generation to generation in families and through various formal and non-formal educational activities; part of Kyrgyz and Kazakh peoples' everyday life, yurt-making provides its practitioners with a sense of identity and continuity and highlights a harmonious relation between nature and human creativity. (3)

The above discussion demonstrate that the Yurt has something intrinsic in it. Yurts are one of the most essential parts of Kyrgyz culture and are more than just houses. They represent the family, the earth, and the universe, and cover everything from birth to death. At present, only the people of Eurasia and Kyrgyz people in particular, are using Yurts for residing in them.

As Yurt has a special value in Kyrgyz traditions, there are several other products which are getting symbolic importance. Some of these products are of very fine quality and being exported in large quantities. Kyrgyz agriculture products are very much appreciated by international buyers especially the neighboring countries. These products such as honey, milk and butter, beans and meat have distinctive features like their taste, fineness, price and quality.

Objective of using Yurts as a Marketing tool. Soon after the collapse of Soviet Union, the independent states were facing an identity crisis. Each of the independent state had to think about something which can symbolize their individuality among the other newly born states. Thus, different states took the help of different instruments e.g. historical figures and personalities, ancient monuments and modern building and dams, symbols and crafts to demonstrate their specificity among the cluster of similar states.

It was the best time to use Yurt as a symbol of Kyrgyz identity. Some political parties, TV channels and local food manufacturers used a logo similar to the Yurt but there was no vivid effort done by any organization to promote Yurt in its original shape. Dairy products (which were of export quality) had a chance to promote Yurt logo, but they used cows and meadows for branding of their products. Kyrgyz honey is very famous and exported world wide but Kyrgyz honey exporters also relied on an image of beer like all the honey exporters worldwide and forgot about their own Yurts.

A temporal effort is made by recent government to highlight the glory of Kyrgyz Yurts by using them in World Nomadic Games. A city of Yurts was built to host the sportsmen coming from participating countries. Especially, an eye-catching scenery of Kyrgyz mountains with a camp built for sportsmen a very positive image of the Kyrgyzstan all over the world.

Besides sports, many other export quality products are unable to gain the respect in international markets which they deserve. Either their effect is neutralized by the marketing campaigns of the products of neighboring countries or their impact is diluted by the large quantity of similar product from another country. The objective to this proposal is to propagate the Yurt Craft knowledge in international arena. As Kyrgyzstan is facing a branding challenge for its products. A Yurt used a logo can be used for both purposes, to market Kyrgyz products and to market Yurt itself.

Scope of using Yurts for Agriculture Products. Yurt is a multi-functional product. We have proposed in one of our recent papers that if Yurtas are made and packed on a commercial scale with a compactable packing for ease in transportation then they can prove to be a better refugee shelter in contrast to UNHCR's models or other traditional refugee shelters. (4)

Yurt still has a huge potential to be used as Kyrgyz emblem whereas present national emblem used in state stamps has a bird, mountains, sun but lacks Yurt. Whereas, a Yurt can easily be added on this present emblem.

Kyrgyz agricultural products of high quality are facing huge competition from Uzbek and Kazakh products. Once these agriculture products bought by other big international buyers, they lose their identity. A yurt added on all the agriculture products especially on honey and dairy products can personalize these products to the Kyrgyzstan. These products of high quality can easily be differentiated from the rival products just because of the presence of the Yurt logo on their packings.

Talas region of Kyrgyzstan is famous for the production of beans. A recent news report claims that since the beginning of 2017, the Talas region has exported 30,110 tons of beans to Turkey, Russia, Kazakhstan, Bulgaria, the Czech Republic and other countries. (5) The irony is that, besides this large quantity, the Talas region in particular and Kyrgyzstan in general is unable to gain its status in international bean market. The only reason is that this quantity is coming from formal and informal 
exporters who ignore to brand it and sell it without any labelling. A state level intervention should ensure that the agriculture products of export quality as of Talas Beans should be exported by using Yurt on their logos so that the international market could recognize its origin and Kyrgyzstan could get better marketing from it.

As a beer is personalize with honey and cow is personalized with dairy products, Yurt can be personalized with all the agricultural products originating from the Kyrgyzstan. At the same time, the craftsmanship affiliated with Yurt crafting with also be promoted and tourism industry will flourish.

Conclusions. Kyrgyzstan is still passing through a transitional period where each marketing instrument is very important to overcome the challenges faced by its identity. Kyrgyzstan as an emerging economy needs to establish its own brands and to highlight its products in international markets which is not possible without personalizing them to something purely of Kyrgyz nature. There are other competitors in the region who have similar products which can neutralize and dilute the impact of Kyrgyz products in international markets. Yurt is being used by Kazakhs and Mongols as well, so Kyrgyz Yurt needs to be personalized somehow with Kyrgyz people only. This is only possible by selling it as a logo and brand with those products which are of export quality. Kyrgyz beans from Talas region have a huge market but no branding. A logo with a Yurt can be used while exporting beans. Thus, beans and Yurt, both can be personalized with Kyrgyzstan. Kyrgyz national emblem lacks a Yurt in it which can easily be added to it. State should intervene to save the Yurt craftsmanship and to get the full fledge benefit from its exported products. One of the strategies to get this desired goal is to use Yurt as a marketing tool for Kyrgyz agricultural products.

\section{REFERENCES}

1. Nomadic Life and Yurts in Kyrgyzstan. Accessed at http://factsanddetails.com/centralasia/Kyrgyzstan/sub8_5b/entry-4763.html

2. Adavtour, Yurts, Kyrgyzstan, Accessed at https://www.advantour.com/kyrgyzstan/ culture/yurts.htm

3. UNESCO, Traditional knowledge and skills in making Kyrgyz and Kazakh yurts (Turkic nomadic dwellings), Accessed at https://ich.unesco.org/en/RL/traditional-knowledge-and-skills-inmaking-kyrgyz-and-kazakh-yurts-turkic-nomadic-dwellings-00998

4. Younas, Ammar, Nomadic Yurtas as an Alternate Habitat for Refugees and Post-Disaster Communities (April 17, 2018). Available at SSRN: https://ssrn.com/abstract=3164547

5. Anastasia Bengard, 24.kg news agency, More than 30,000 tons of Talas beans exported in 2017, Accessed at https://24.kg/english/66297_More_than_30000_tons_of_Talas_beans_exported_in_2017/ 